\title{
Mechanism of Uptake of Cobalamin into Enterocyte Mitochondria
}

\author{
Masami INADA and Masanori TOYOSHIMA ${ }^{1}$ \\ Department of Geriatrics, Kyoto University Hospital, \\ Kawaramachi, Shogoin, Sakyo-ku, Kyoto 606, Japan
}

(Received November 6, 1981)

\begin{abstract}
Summary To study the mechanism which cobalamin is taken up by the mitochondria, ${ }^{57}$ Co-cyanocobalamin-binder complex and freshly prepared mitochondria were prepared from the enterocytes of rats. Subsequently, the binder complex was incubated together with mitochondria in a calcium-containing medium in vitro. Uptake of cobalamin was determined by measuring the radioactivities bound to the mitochondria. Consequently, lysosomal and microsomal binders enhanced cobalamin uptake into the mitochondria, but intrinsic factor did not.

It was found that the uptake into the mitochondria was inhibited by previous treatment with calcium-chelating agents. The uptake was completely restored after addition of calcium ions to the mitochondria.

Key Words uptake mechanism, cobalamin, intracellular binder, lysosomal binder, mitochondria, transcobalamin II, intrinsic factor, rat enterocytes, calcium ions, calcium-chelating agent
\end{abstract}

It has been shown in our laboratory that cobalamin absorbed into enterocytes is transported to circulating blood by the aid of lysosomes $(1)$. In the mitochondria of guinea pig enterocytes where cobalamin concentrations are the highest among all the subcellular fractions, there was found a large amount of endogeneous cobalamin. Therefore, cobalamin must have an important role in the mitochondria, where interconversion of cobalamins has been suspected to occur (2). The existence of specific mechanisms by which the uptake of cobalamin from the intracellular environment into mitochondria could be facilitated has also been suspected. To clarify the mechanism, uptake of cobalamin into the mitochondria was studied here in vitro using rat enterocytes. The $K_{\mathrm{m}}$ values for the reaction between intracellular binders and mitochondrial receptors were also determined.

\section{MATERIALS AND METHODS}

Animals. Three-month-old Wistar rats weighing $300 \mathrm{~g}$ were used. Before sacrifice, they were fasted for $24 \mathrm{hr}$ and water was given ad libitum.

1 稲田雅美, 豊島正憲 
Preparation of subcellular fractions (3). Rats were killed by drawing blood from the heart under slight anesthesia. The small intestine was removed and the mucosal surface was washed with an ice-cold sucrose solution for the complete removal of foods and faeces.

Mucosal scrapings were homogenized in $0.25 \mathrm{~m}$ sucrose Tris- $\mathrm{HCl}$ buffer, $\mathrm{pH}$ 7.8 , by up-and-down pestling five times. Subcellular fractions were separated using a modified method of differential ultracentrifugation $(4,5)$. The purity of each fraction was assessed by measuring specific activities of marker enzymes. The lysosomal and microsomal fractions were used for the preparation of lysosomal and microsomal binders, which were separated by gel filtration using Sephadex G-200 (Pharmacia Fine Chemicals, Uppsala, Sweden) and anion-exchanger column chromatography using DEAE-cellulose (capacity $0.91 \mathrm{mEq} / \mathrm{g}$; Brown Co., N. Y., U.S.A.). The mitochondrial fractions were used for preparing fresh mitochondrial suspensions.

Preparation of lysosomal and microsomal binders (3). ${ }^{57} \mathrm{Co}$-cyanocobalamin was added to lysosomal and microsomal fractions to saturate their binding capacities. As the first step, lysosomal and microsomal binders were separated using the gel filtration technique on a $2 \times 28 \mathrm{~cm}$ Sephadex column. Radioactive eluates containing these binders were collected, concentrated, dialyzed, and buffered against $0.01 \mathrm{~m}$ phosphate buffer $\mathrm{pH}$ 7.5. As the second step, the sample was applied to a $2 \times 28 \mathrm{~cm}$ DEAE-cellulose column to purify the binders by step-wise elution

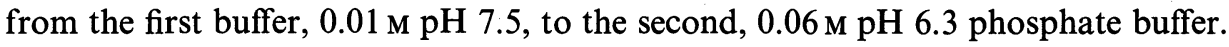
Eluates obtained with $0.01 \mathrm{M}$ phosphate buffer were used as the cobalaminlysosomal binder complex or cobalamin-microsomal binder complex in this experiment.

Preparations of rat transcobalamin II and rat intrinsic factor. Transcobalamin II and intrinsic factor were prepared from the sera and gastric juice of rats for comparison of the cobalamin uptake of these binders with that of lysosomal or microsomal binders. Transcobalamin II and intrinsic factor were separated by the method of Retief et al. (6). These binders were also used for the uptake experiments.

System of uptake of cobalamin into mitochondria. Mitochondria were separated by differential ultracentrifugation. To saturate non-specific cobalamin binding on the mitochondria, a non-radioactive cobalamin solution was added to the mitochondria before incubation. Washing of the mitochondrial suspensions with saline was repeated several times for the complete elimination of unbound cobalamin. Finally, the fresh mitochondria thus prepared were used by adding them to incubation mixtures in the uptake system. In this system, suspensions of the mitochondria were prepared as shown in Table 1. A control experiment was carried out by using a solution containing ${ }^{57} \mathrm{Co}$-cyanocobalamin alone instead of ${ }^{57} \mathrm{Co}-$ cobalamin binder complexes.

The mixtures in this system were incubated at $37^{\circ} \mathrm{C}$ for $1 \mathrm{hr}$. After the incubation, ${ }^{57} \mathrm{Co}$-cyanocobalamin not bound to mitochondria was removed by repeated washing with calcium-containing solutions and subsequent centrifugation. 
Table 1. System for uptake of cobalamin into mitochondria.

\begin{tabular}{cccc}
\hline $\begin{array}{c}\mathrm{CaCl}_{2} \text {-saline } \\
(\mathrm{ml})\end{array}$ & ${ }^{57} \mathrm{Co}-\mathrm{Cbl}$ & $\begin{array}{c}{ }^{57} \mathrm{Co}-\mathrm{Cbl}= \\
\text { binder } \\
\text { complexes }\end{array}$ & $\begin{array}{c}\text { Suspensions of } \\
\text { mitochondria } \\
(\mathrm{ml})\end{array}$ \\
\hline 2.0 & $1.0 \mathrm{ml}$ & - & 0.5 \\
\hline 2.0 & - & $\begin{array}{c}1.0 \mathrm{ml} \\
{ }^{57} \mathrm{Co}-\mathrm{Cbl}= \\
\text { L-binder }\end{array}$ & 0.5 \\
\hline 2.0 & - & $\begin{array}{c}{ }^{57} \mathrm{Co}-\mathrm{Cbl}= \\
\mathrm{M}-\mathrm{binder}\end{array}$ & 0.5 \\
\hline 2.0 & - & $\begin{array}{c}{ }^{57} \mathrm{Co}-\mathrm{Cbl}= \\
\mathrm{IF}\end{array}$ \\
\hline
\end{tabular}

Tc II, transcobalamin II; ${ }^{57} \mathrm{Co}-\mathrm{Cbl} ;{ }^{57} \mathrm{Co}$-cyanocobalamin; L-binder, lysosomal binder; M-binder, microsomal binder; IF, intrinsic factor.

Radioactivity contained in the sediment was counted for ${ }^{57} \mathrm{Co}$ as the cobalamin taken up by the mitochondria. The net uptake into the mitochondria was calculated by subtraction of the control uptake.

Determination of protein concentrations of the binders and the mitochondrial fractions. To compare the results obtained from each experiment, protein concentrations of binders and mitochondrial suspensions used in each incubation system were measured by Lowry's method (7). Each final result was expressed as pg cobalamin/mg protein of the mitochondria.

Studies of $K_{\mathrm{m}}$-values for intracellular binders and receptors on mitochondria. Mitochondrial fractions previously saturated with non-radioactive cobalamin were suspended in the incubation mixture. The solutions of purified intracellular binders were placed in centrifuge tubes in two-fold serial dilution (Table 2). Finally, a similar amount of the solution containing ${ }^{57} \mathrm{Co}$-cyanocobalamin and nonradioactive cyanocobalamin was added to the incubation system in the same tubes. The uptake into the mitochondria was determined in a similar way after incubation of the system.

Effects of calcium-chelating agent on uptake of cobalamin into the mitochondria. In the step of mitochondrial preparation, the calcium-chelating agent EDTA-Na remaining in the suspensions was completely removed by washing twice with normal saline. The resulting mitochondrial suspension was used for the incubation to determine whether or not calcium ions are necessary for the uptake of cobalamin Vol. 28, No. 3, 1982 
Table 2. Serial dilution system for binder complexes in the uptake into mitochondria. Each solution was added to the system in this order. Radio-cobalamin binder complex was diluted as in this table.

\begin{tabular}{ccccc}
\hline & $\begin{array}{c}\mathrm{CaCl}_{2} \text {-saline } \\
(\mathrm{ml})\end{array}$ & $\begin{array}{c}{ }^{57} \mathrm{Co}-\mathrm{Cbl} \\
(\mathrm{ml})\end{array}$ & $\begin{array}{c}{ }^{57} \mathrm{Co}-\mathrm{Cbl}= \\
\text { binder } \\
\text { complexes } \\
(\mathrm{ml})\end{array}$ & $\begin{array}{c}\text { Suspensions of } \\
\text { mitochondria } \\
(\mathrm{ml})\end{array}$ \\
\hline 1 & 2.0 & - & 1.0 & 0.5 \\
\hline 2 & 2.0 & 0.5 & 0.5 & 0.5 \\
\hline 3 & 2.0 & 0.75 & 0.25 & 0.5 \\
\hline 5 & 2.0 & 0.9 & 0.1 & 0.5 \\
\hline
\end{tabular}

${ }^{57} \mathrm{Co}-\mathrm{Cbl},{ }^{57} \mathrm{Co}-$ cyanocobalamin.

into mitochondria. Readdition of calcium ions to the mitochondrial suspensions treated with EDTA-Na solution was made to observe the recovery from inhibition.

\section{RESULTS}

Purity of each subcellular fraction (3)

The content of each enzymes specific to the individual subcellular fractions was over 5 times that of the homogenate. A large number of mitochondria was found to be contained in the mitochondrial fraction electron-microscopically, although a little contamination was noted. Therefore, subcellular fractions used were found to be partially purified.

\section{Physico-chemical properties of the binders}

In gel filtration, eluates containing ${ }^{57} \mathrm{Co}$-radioactivity obtained at the elution site were of a molecular weight of around 40,000 , similar to transcobalamin II. Therefore, the molecular weight of this binder is completely different from those of the several cobalamin-dependent holoenzymes. The isoelectric point of this binder was shown to be between 5.0 and 6.25 .

Enhancement of uptake of cobalamin into mitochondria by these binders

The uptake of ${ }^{57} \mathrm{Co}$-cobalamin added to the incubation system was found to be enhanced by lysosomal and microsomal binders, while enhancement did not occur in the system of ${ }^{57} \mathrm{Co}$-cobalamin alone (Fig. 1). Transcobalamin II-cobalamin complex caused a considerable enhancement of uptake by mitochondria. However, 


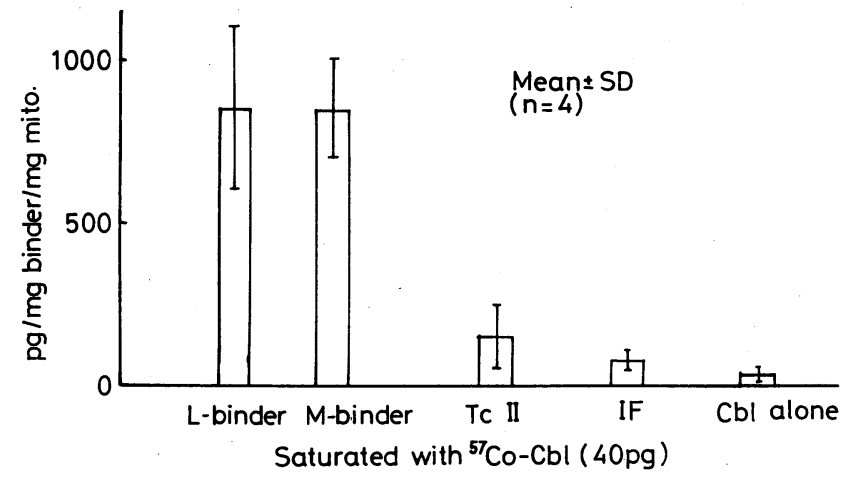

Fig. 1. Effects of cobalamin binders on the uptake of cobalamin into the mitochondria. L-, M-binder, Tc II, IF, and Cbl represent lysosomal binder, microsomal binder, transcobalamin II, intrinsic factor, and cobalamin, respectively.

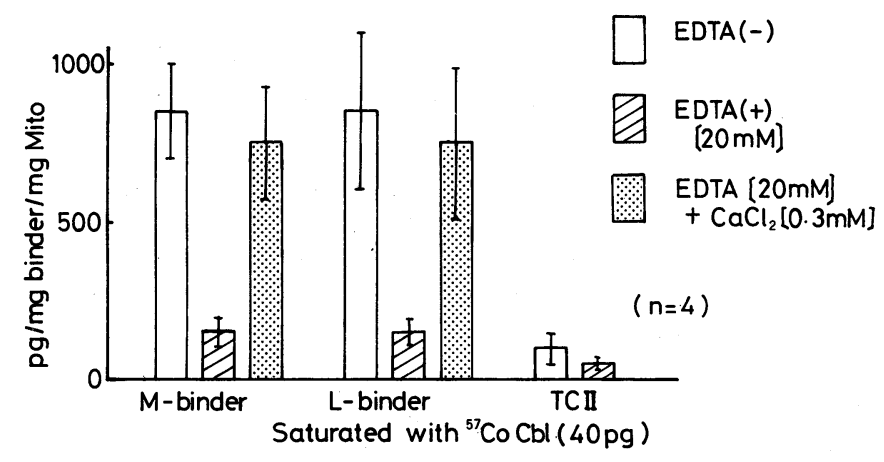

Fig. 2. Effects of calcium-chelating agent (EDTA) on the uptake of cobalamin into the mitochondria. Previous treatment of the mitochondrial suspensions with EDTA proved to lower the uptake markedly as shown in the oblique-lined columns. The uptake was restored to normal after the addition of calcium ions as shown in the shaded column.

intrinsic factor did not enhance the uptake any further. When the uptake was expressed by pg cobalamin / $\mathrm{mg}$ binder / $\mathrm{mg}$ protein mitochondria, lysosomal and microsomal binders were found to cause the maximum uptake among the four binders. Transcobalamin II showed a considerably high uptake, but this was low in terms of per mg protein possibly due to the contaminating by serum proteins in the transcobalamin II solution used. There was no difference between the uptakes of lysosomal and microsomal binders.

Effects of calcium-chelating agent on uptake of cobalamin into mitochondria

In the mitochondria previously treated with EDTA, inhibition of uptake Vol. 28, No. 3, 1982 

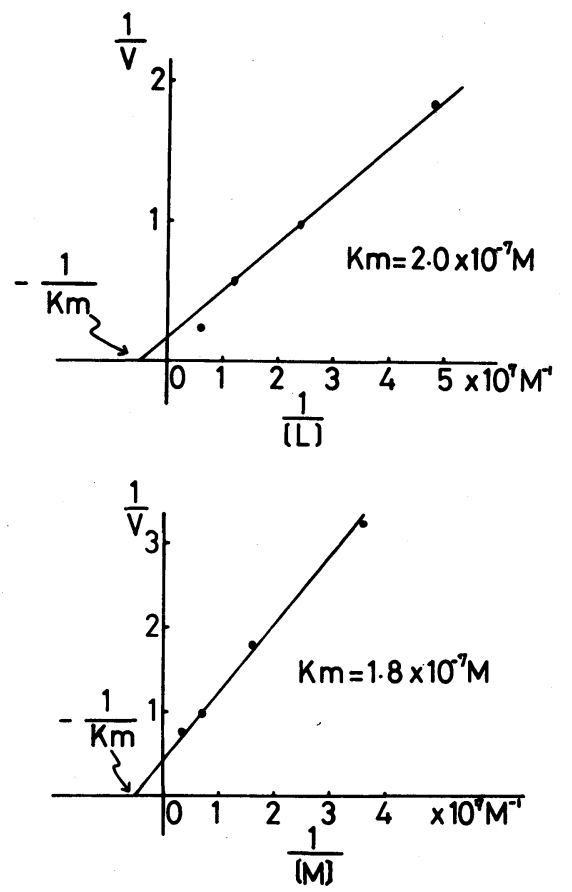

Fig. 3. Evaluations of $K_{\mathrm{m}}$ between lysosomal binder (L) or microsomal binder (M) and mitochondria.

occurred, as shown in Fig. 2. In constract, addition of calcium ions to the EDTAtreated mitochondria led to almost complete recovery from the blocked uptake.

$K_{\mathrm{m}}$ values of mitochondrial receptors and intracellular binders

The $K_{\mathrm{m}}$ for the reaction between lysosomal binder and its receptor on the mitochondria, proved to be $2.0 \times 10^{-7} \mathrm{M}$, and that for microsomal binder and its receptor $1.8 \times 10^{-7} \mathrm{M}$. Thus, no apparent difference was noted between lysosomal and microsomal binders.

\section{DISCUSSION}

Lysosomal and microsomal binders were found to enhance the uptake of cobalamin into the mitochondria in rat enterocytes. From these observations, these binders seem to be transport binders specific to the intracellular organellae, especially to the mitochondria. Transcobalamin II is required for uptake of cobalamin into mitochondria obtained from rat liver $(8)$. This is somewhat similar to the selective binding of intrinsic factor to the intestinal mucosal receptor or the binding of transcobalamin II to the cell receptor in tissues.

The surface of the mitochondrion seems to have a receptor for the intracellular 
binders in the enterocytes. The intracellular binders have a characteristic intermediate between intrinsic factor and transcobalamin II. The intracellular binder has an isoelectric point slightly lower than that of transcobalamin II and slightly higher than that of intrinsic factor as judged from the pattern of adsorption to zirconium in our laboratory (9). Intrinsic factor has more negative charges than transcobalamin II. These differences may arise from the contents of sialic acid on the surface of each molecule. The relationships between the cobalamin binders and the surface receptors might be explained by the charges in the surface structure of both molecules, which have a key-key hole relation.

Calcium ions seem to have an important role also in the uptake of cobalamin into mitochondria. This may suggest that calcium ions have important roles to play in maintaining the normal surface structure of the mitochondrion. It has been reported that addition of an EDTA-Na solution to fresh red cells causes deformation of irregular uneven surfaces of the red cells on electron-microscopic observations $(10)$. Based on this finding, it seems that the surface of the brush borders of the mucosa is also distorted. Therefore, the binder might be unable to bind with the receptor on the mitochondrion. There are several metabolic inhibitors besides EDTA-Na. Iodoacetate and $\mathrm{NaCl}$ are both known to inhibit cobalamin transport in Ehrlich ascites carcinoma cells (11). Similarly, they may possibly inhibit transport to the mitochondrion. Dithiothreitol(12), actinomycin-D, and 2,4dinitrophenol have been shown to cause strong inhibition of uptake by HeLa cells, leading to $80-100 \%$ inhibition.

It was found that there exist cobalamin binders specific to various locations: transport to the brush border of enterocytes by intrinsic factor, to erythrocytes (13) and leukemic lymphoblasts (14) by transcobalamin II, to liver cells by transcobalamin II, and to mitochondria by intracellular binders, especially to the mitochondria of enterocytes by lysosomal and microsomal binders in our laboratory. The individual mechanisms of cobalamin transport seem to be almost the same.

\section{REFERENCES}

1) Inada, M., Toyoshima, M., and Kameyama, M. (1979): Intracellular transport of vitamin $\mathrm{B}_{12}$ in enterocytes, in Vitamin $\mathrm{B}_{12}$, ed. by Zagalak, B., and Friedrich, W., Walter de Gruyter, \& Co. Berlin, pp. 919-920.

2) Peters, T. J., and Hoffbrand, A. V. (1970): Absorption of vitamin $B_{12}$ by guinea pig. Br. J. Haematol., 19, 369-382.

3) Inada, M., and Miyata, S. (1975): Studies on mechanisms of vitamin $B_{12}$ absorption in the intestine. (I) Separation of vitamin $B_{12}$ binders in rat enterocytes. Vitamins (in Japanese), 49, 105-110.

4) Robinson, G. B. (1963): The distribution of peptidases in subcellular fractions from the mucosa of the small intestine of the rat. Biochem. J., 88, 162-168.

5) Hübscher, G., West, G. R., and Brindley, D. N. (1965): Studies on the fractionation of mucosal homogenates from the small intestine. Biochem. J., 97, 629-642.

6) Retief, F. P., Gottlieb, C. W., Kochwa, S., Pratt, P., and Herbert, V. (1967): Separation

Vol. 28, No. 3, 1982 
of vitamin $B_{12}$ binding proteins of serum, gastric juice, and saliva by rapid DEAEcellulose chromatography. Blood, 29, 837-851.

7) Lowry, O. H., Rosebrough, N. J., Farr, A. L., and Randall, R. J. (1951): Protein measurement with the Folin phenol reagent. J. Biol. Chem., 193, 265-275.

8) Gams, R. A., Ryel, E. M., and Ostroy, F. (1976): Protein-mediated uptake of vitamin $\mathrm{B}_{12}$ by isolated mitochondria. Blood, 47, 923-930.

9) Inada, M., and Miyata, S. (1975): Simplified assay for rat intrinsic factor by zirconium gel method. Vitamins (in Japanese), 49, 171-175.

10) Pinteric, L., Manery, J. F., Chaudry, I. H., Madapallimattam, C. T. (1975): The effects of EDTA, cations, and various buffers on the morphology of erythrocytes membranes: An electronmicroscopic study. Blood, 45, 709-724.

11) Paranchych, W., and Cooper, B. A. (1962): Factors influencing the uptake of cyanocobalamin (vitamin $\mathrm{B}_{12}$ ) by Ehrlich ascites carcinoma cells. Biochim. Biophys. Acta, 60, 393-403.

12) Finkler, A. E., Hall, C. A., Dean, C., and Green, P. D. (1970): Chemical modification of the active site of transcobalamin II-B B $_{12}$ receptor. Fed. Proc., 29, 876.

13) Retief, F. P., Gottlieb, C. W., and Herbert, V. (1966): Mechanism of vitamin $B_{12}$ uptake by erythrocytes. J. Clin. Invest., 45, 1907-1915.

14) Ryel, E. M., Meyer, L. M., and Gams, R. A. (1974): Uptake and subcellular distribution of vitamin $B_{12}$ in mouse L 1210 leukemic lymphoblasts. Blood, 44, 427-433. 